\title{
Comparison of early postnatal prediction models for survival in congenital diaphragmatic hernia
}

\author{
Mehtab K. Sekhon $\mathbb{1}^{1} \cdot$ Stephen J. Fenton ${ }^{2} \cdot$ Bradley A. Yoder ${ }^{1}$
}

Received: 3 September 2018 / Revised: 2 January 2019 / Accepted: 14 January 2019 / Published online: 15 February 2019

(c) Springer Nature America, Inc. 2019

\begin{abstract}
Objective To compare the PF-PCO $\mathrm{PC}_{2}$ equation - partial pressure of arterial oxygen $\left(\mathrm{PaO}_{2}\right) /$ fraction of inspired oxygen $\left(\mathrm{FiO} \mathrm{O}_{2}\right)$ minus partial pressure of carbon dioxide $\left(\mathrm{PCO}_{2}\right)$ - to three other tools for postnatal prediction of survival in infants with congenital diaphragmatic hernia (CDH).

Study design A retrospective analysis of 203 infants with CDH from 1 January 2003 to 30 June 2018. Area under the curve (AUC) analysis was performed for survival and secondary outcomes of survival without extracorporeal membrane oxygenation support (ECMO) and death despite ECMO. Predictive scores were calculated to determine cutoff for $\mathrm{PF}^{\mathrm{PCO}} \mathrm{PC}_{2}$ score.

Results The PF- $\mathrm{PCO}_{2}$ tool had the highest AUC (0.84 for survival, 0.92 for survival without ECMO, and 0.83 for death despite ECMO). PF-PCO ${ }_{2}$ best predicted survival when $>-60$ and survival without ECMO when $>+80$. There was no optimal cutoff score for death despite ECMO.
\end{abstract}

Conclusion The PF- $\mathrm{PCO}_{2}$ tool best predicted postnatal survival in infants with $\mathrm{CDH}$.

\section{Introduction}

Congenital diaphragmatic hernia $(\mathrm{CDH})$ occurs in $\sim 1$ in 3000 live births and has a mortality rate between $20-40 \%$ [1-4]. Prenatal predictors of survival, based on ultrasound and magnetic resonance imaging findings $[5,6]$, can aid in prenatal counselling of families regarding survival and prognosis. Ultimately, the severity of pulmonary hypoplasia and ability to oxygenate and ventilate determines survival in these patients $[2,7-10]$.

Several postnatal models for predicting survival of infants with $\mathrm{CDH}$ have been developed and tested in both local populations and the Congenital Diaphragmatic Hernia Study Group (CDHSG) registry, which includes infants with $\mathrm{CDH}$ from North America, Europe, and Australia. These include tools created specifically for infants with

Mehtab K. Sekhon

maggie.sekhon@hsc.utah.edu

1 Division of Neonatology, University of Utah School of Medicine, Salt Lake City, UT, USA

2 Division of Pediatric Surgery, University of Utah School of Medicine, Salt Lake City, UT, USA
$\mathrm{CDH}$, such as the CDHSG Probability of Survival Equation (CDHSG-PS) [1], Wilford Hall Santa Rosa Prediction Formula (WHSRpf) [8], and Brindle tool [11], as well as predictors of morbidity and mortality in general neonatal and pediatric populations [12, 13]. No postnatal prediction tool is applied consistently across institutions caring for infants with $\mathrm{CDH}$. Furthermore, problems with existing tools include poor generalizability and difficulty in calculating a score at the patient's bedside.

Of the tools developed specifically for the CDH population, the WHSRpf tool includes measures of oxygenation and ventilation. This equation is the difference between the best partial pressure of arterial oxygen $\left(\mathrm{PaO}_{2}\right)$ and partial pressure of carbon dioxide $\left(\mathrm{PaCO}_{2}\right)$ in the first $24 \mathrm{~h}$ of life [8]. However, $\mathrm{PaO}_{2}$ alone is a poor measure of hypoxemia. Thus, we modified the WHSRpf equation to include the $\mathrm{PaO}_{2}$ /fraction of inspired oxygen $\left(\mathrm{FiO}_{2}\right)(\mathrm{PF})$ ratio to better account for the degree of hypoxemia in infants with $\mathrm{CDH}$ $[14,15]$. The final equation we refer to as the $\mathrm{PF}^{-\mathrm{PCO}_{2}}$ tool, or the difference between the $\mathrm{PF}$ ratio and $\mathrm{PCO}_{2}$, where $\mathrm{PaO}_{2}$ and $\mathrm{PaCO}_{2}$ are the best values (not necessarily from the same blood gas) obtained in the first $24 \mathrm{~h}$ of life and $\mathrm{FiO}_{2}$, is the $\mathrm{FiO}_{2}$ recorded at the same time as the $\mathrm{PaO}_{2}$. Chandrasekharan et al. have also described this equation in a brief letter to the editor [16]. 
Table 1 Models for postnatal prediction of survival in $\mathrm{CDH}$

\begin{tabular}{lll}
\hline Model & Formula & Cutoff \\
\hline CDHSG-PS & $1-\left[1 /\left(1+\mathrm{e}^{-\mathrm{x}}\right)\right]$ & Low risk mortality $=0-33 \%$ \\
& $-\mathrm{x}=5.0240+0.9165$ (birth weight $)+0.4512(5$ & $\begin{array}{l}\text { Moderate risk mortality }=34-66 \% \\
\text { High risk mortality }=67-100 \%\end{array}$ \\
WHSRpf & $\mathrm{PaO} 2-\mathrm{PCO} 2$ & $\geq 0=$ low risk of mortality \\
Brindle tool & 1 point each for: low birth weight $(<1500 \mathrm{~g})$, low & $0=$ low risk of death $(<10 \%)$ \\
& Apgar score $(<7)$, and major cardiac anomaly & $1-2=$ Intermediate risk of death $(25 \%)$ \\
& 2 points each for: missing Apgar and severe & $\geq 3=$ high risk of death $(50 \%)$ \\
& pulmonary hypertension & \\
\hline
\end{tabular}

${ }^{a}$ Major cardiac anomaly - all anomalies other than patent ductus arteriosus and patent foramen ovale

${ }^{\mathrm{b}}$ Severe pulmonary hypertension-right to left shunting across a patent ductus arteriosus or estimates of pulmonary pressures
Given the importance of a clinical prediction tool in guiding therapy and postnatal counseling, we performed a retrospective review comparing the equation, $\mathrm{PF}-\mathrm{PCO}_{2}$, with three other published tools (CDHSG-PS, WHSRpf, and Brindle score) to predict survival in our local population of $\mathrm{CDH}$ infants. We also determined the predictive ability of this equation for the secondary outcomes of survival without extracorporeal membrane oxygenation support (ECMO) and death despite ECMO. Our hypothesis was that the PF-PCO $\mathrm{PCol}_{2}$ will be most predictive of survival, survival without ECMO, and death despite ECMO.

\section{Methods}

Eligible infants were identified retrospectively from an internal database of infants with $\mathrm{CDH}$ admitted to the University of Utah or Primary Children's Hospital Neonatal Intensive Care Units (NICU's) from 1 January 2003 to 30 June 2018. This database contains prospectively captured data on each infant, including need for ECMO and measures of ventilation and oxygenation, including blood gas $\left(\mathrm{PaO}_{2}\right.$ and $\left.\mathrm{PaCO}_{2}\right)$ and ventilator support data $\left(\mathrm{FiO}_{2}\right.$ and mean airway pressure) at various time points. Infants admitted to the University of Utah or Primary Children's NICU's pre-repair were eligible for this study. Exclusion criteria were diagnosis of $\mathrm{CDH}$ after $24 \mathrm{~h}$ of life, gestational age less than $34^{0 / 7}$ weeks, birth weight less than $1800 \mathrm{~g}$, and presence of other major anomalies or chromosomal disorders. All infants were repaired at our center. Major cardiac anomalies were defined as all cardiac anomalies except for patent foramen ovale, patent ductus arteriosus, ventricular septal defect, or atrial septal defect.

CDHSG-PS, WHSRpf, and Brindle scores were calculated for all eligible infants based on previously published formulae (Table 1).(1,8,11) $\mathrm{PF}-\mathrm{PCO}_{2}$ was calculated for all eligible infants per the formula $-\left[\mathrm{PaO}_{2} / \mathrm{FiO}_{2}\right]-\mathrm{PaCO}_{2}-$ where $\mathrm{PaO}_{2}$ and $\mathrm{PaCO}_{2}$ are the highest and lowest values, respectively, from post-ductal arterial blood gases obtained in the first $24 \mathrm{~h}$ of life. The $\mathrm{FiO}_{2}$ is the value recorded at the time of the $\mathrm{PaO}_{2}$. Institutional review board approval and a waiver of informed consent due to retrospective nature of the study were obtained from the University of Utah and Primary Children's Hospital.

The primary outcome was the ability of each tool to predict survival. Secondary outcomes included: ability of the $\mathrm{PF}-\mathrm{PCO}_{2}$ tool to predict survival without ECMO and death despite ECMO; and defining cutoff values that best predict all outcomes for the PF-PCO ${ }_{2}$ tool. To determine these cutoff points, positive (PPV) and negative predictive values (NPV) were calculated for the $\mathrm{PF}-\mathrm{PCO}_{2}$ tool at intervals of 20 from -80 to +80 .

The primary outcome and other categorical measures were analyzed by Chi-square or Fisher's Exact test. Student's $t$-test was used for analysis of normally distributed continuous data and Mann-Whitney $U$ test was applied for ordinal data or continuous data that was not normally distributed. Two-sided $P$-values less than 0.05 were considered statistically significant and no adjustment was made for multiple comparisons. Area under the curve analysis was performed. SPSS (version 24, IBM, Armonk NY) was used for statistical analysis.

\section{Results}

Figure 1 shows the patient flowchart. After exclusion of 70 infants, the final study group of 203 included 165 infants who survived and 38 infants who died. Within each group, missing data precluded WHSRpf and PF$\mathrm{PCO}_{2}$ score calculation for seven infants. Of the 19 infants diagnosed with $\mathrm{CDH}$ after $24 \mathrm{~h}$ of life, two $(11 \%)$ were born at $<34$ weeks GA and $<1800 \mathrm{~g}$ and three $(16 \%)$ had a severe anomaly. The remaining 14 infants diagnosed after $24 \mathrm{~h}$ of life underwent primary repair of their defect and survived without ECMO. Missing data precluded 


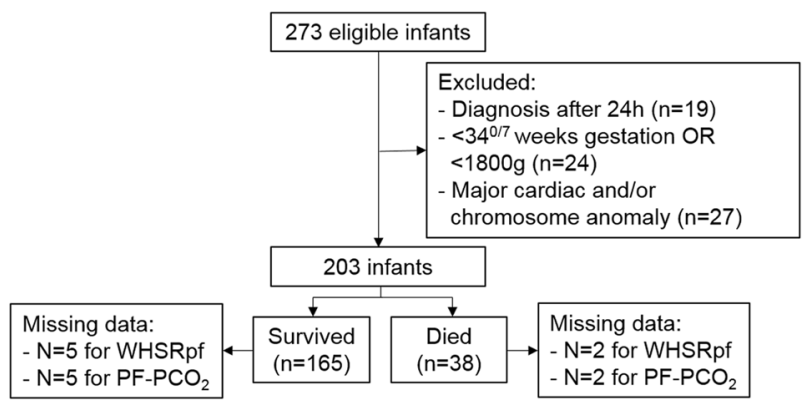

Fig. 1 Patient flowchart. WHSRpf Wilford Hall Santa Rosa Prediction Formula, $P F-P C O_{2}\left(\mathrm{PaO}_{2} / \mathrm{FiO}_{2}\right)-\mathrm{PCO}_{2}$ equation

PF-PCO ${ }_{2}$ calculation for these infants. Patient characteristics are shown in Table 2. Infants who survived had a higher birth weight, but this was not statistically significant. They were also less likely to have pulmonary hypertension pre-repair, liver in the thorax, and to undergo ECMO. There was a significant difference in type of repair, with surviving infants more likely to undergo primary repair $(p<0.001)$. There were no differences in survival $(p=0.119)$ or ECMO use $(p=0.322)$ when infants were divided into 5 -year epochs corresponding to their birth year $(1=2003-2007,2=2008-2012$, and $3=$ 2013-2018). This was also true on regression analysis, where birth epoch did not influence survival $(p=0.057$ for epoch 1 versus $3 ; p=0.079$ for epoch 2 versus 3 ). For the PF- $\mathrm{PCO}_{2}$ and WHSRpf equations, the median age of the highest $\mathrm{PaO}_{2}$ and lowest $\mathrm{PaCO}_{2}$ values was $7 \mathrm{~h}$ (interquartile range 3-14 h) and $6 \mathrm{~h}(4-14 \mathrm{~h}$ ), respectively. There was a significant difference in the median predictive score for each tool between groups (Table 2).

As seen in Fig. 2, the $\mathrm{PF}^{-\mathrm{PCO}_{2}}$ tool best predicted survival, with an AUC of 0.84 (95\% confidence interval (CI) $0.77-0.91$ ), versus 0.80 (95\% CI 0.72-0.88) for WHSRpf, 0.77 (95\% CI 0.69-0.86) for CDHSG-PS. The AUC's for the Brindle score are not included in the figure as they are inversely related to the other scores. The AUC for survival by the Brindle tool was the lowest among the predictive scores tested at 0.74 (95\% CI 0.65-0.83). For survival without ECMO, $\mathrm{PF}-\mathrm{PCO}_{2}$ outperformed the other tools with an AUC of 0.92 (95\% CI 0.87-0.96) versus 0.87 (95\% CI 0.81-0.93) for WHSRpf, 0.72 (95\% CI 0.65-0.80) for CDHSG-PS, and 0.75 (95\% CI 0.68-0.82) for the Brindle tool. Finally, for death despite ECMO, $\mathrm{PF}-\mathrm{PCO}_{2}$ had the highest AUC at 0.83 (95\% CI $0.76-0.91)$ versus $0.82(95 \%$ CI 0.75-0.89) for WHSRpf, 0.75 (95\% CI 0.65-0.85) for CDHSG-PS, and 0.77 (95\% CI 0.67-0.88) for the Brindle tool.

The scatterplot diagram in Fig. 3 shows the distribution of PF-PCO ${ }_{2}$ scores for the outcomes of survival, survival without ECMO, and death despite ECMO. A PF-PCO score $>-60$ was most predictive of survival and $>+80$ was
Table 2 Baseline characteristics of patients in each group

\begin{tabular}{|c|c|c|c|}
\hline & $\begin{array}{l}\text { Survived } \\
N=165\end{array}$ & Died $N=38$ & $P$ \\
\hline $\begin{array}{l}\text { Birth weight, g (mean, } \\
\text { SD) }\end{array}$ & $3138(455)$ & 2995 (637) & 0.109 \\
\hline $\begin{array}{l}\text { Gestational age, weeks } \\
\text { (mean, SD) }\end{array}$ & $38(1)$ & $38(2)$ & 0.079 \\
\hline Inborn & $96(58 \%)$ & $25(66 \%)$ & 0.389 \\
\hline Male sex & $103(62 \%)$ & $26(68 \%)$ & 0.489 \\
\hline Race & & & 0.891 \\
\hline Caucasian & $134(81 \%)$ & $31(82 \%)$ & \\
\hline Hispanic & $21(13 \%)$ & $5(13 \%)$ & \\
\hline African American & $2(1 \%)$ & $1(3 \%)$ & \\
\hline Other & $8(5 \%)$ & $1(3 \%)$ & \\
\hline \multicolumn{4}{|l|}{ Apgar (median, 25-75\%) } \\
\hline $1 \mathrm{~min}$ & 5 (3 to 7$)$ & $2(1$ to 3$)$ & $<0.001$ \\
\hline $5 \mathrm{~min}$ & $7(6$ to 8$)$ & $6(4$ to 7$)$ & $<0.001$ \\
\hline Fetal diagnosis & $99(60 \%)$ & $27(71 \%)$ & 0.206 \\
\hline $\begin{array}{l}\text { Pulmonary hypertension } \\
\text { (pre-repair) }\end{array}$ & $142(86 \%)$ & $38(100 \%)$ & 0.015 \\
\hline Left sided hernia & $148(90 \%)$ & $32(84 \%)$ & 0.336 \\
\hline Liver in thorax & $59(36 \%)$ & $19(50 \%)$ & $<0.001$ \\
\hline Repair type & & & $<0.001$ \\
\hline Primary & $113(68 \%)$ & $5(13 \%)$ & \\
\hline Muscle flap & $41(25 \%)$ & $7(18 \%)$ & \\
\hline Patch & $11(7 \%)$ & $7(18 \%)$ & \\
\hline None & $0(0 \%)$ & $19(50 \%)$ & \\
\hline ECMO & $44(27 \%)$ & $22(58 \%)$ & $<0.001$ \\
\hline Birth epoch & & & 0.119 \\
\hline $1(2003-2007)$ & $53(32 \%)$ & $16(42 \%)$ & \\
\hline $2(2008-2012)$ & $53(32 \%)$ & $15(39 \%)$ & \\
\hline 3 (2013-2018) & $59(36 \%)$ & $7(18 \%)$ & \\
\hline $\begin{array}{l}\text { Predictive score (median, } \\
25-75 \% \text { ) }\end{array}$ & & & $<0.001$ \\
\hline PF-PCO 2 & $182(66$ to 264$)$ & $\begin{array}{l}-7(-36 \text { to } \\
+14)\end{array}$ & \\
\hline WHSRpf & $58(-4$ to +142$)$ & $\begin{array}{l}-34(-55 \text { to } \\
-10)\end{array}$ & \\
\hline CDHSG-PS & 77 (63 to 84$)$ & 51 (30 to 66$)$ & \\
\hline Brindle & $0(0$ to 2$)$ & $2(1$ to 3$)$ & \\
\hline
\end{tabular}

Data as mean (SD) or number $(\%)$, unless otherwise specified in the table

ECMO extracorporeal membrane oxygenation, $I Q R$ interquartile range, $P F-P C O_{2}\left(\mathrm{PaO}_{2} / \mathrm{FiO}_{2}\right)-\mathrm{PCO}_{2}$ equation, WHSRpf Wilford Hall Santa Rosa Prediction Formula, CDHSG-PS Congenital Diaphragmatic Hernia Study Group Probability of Survival Equation

most predictive of survival without ECMO (Table 3). More subjects with a PF-PCO2 score $>-60$ survived $(97 \%, p<$ $0.001)$ and score $>+80$ survived without ECMO $(93 \%, p<$ $0.001)$. The $\mathrm{PF}-\mathrm{PCO}_{2}$ score had poor predictive ability for the outcome of death despite ECMO. 
A

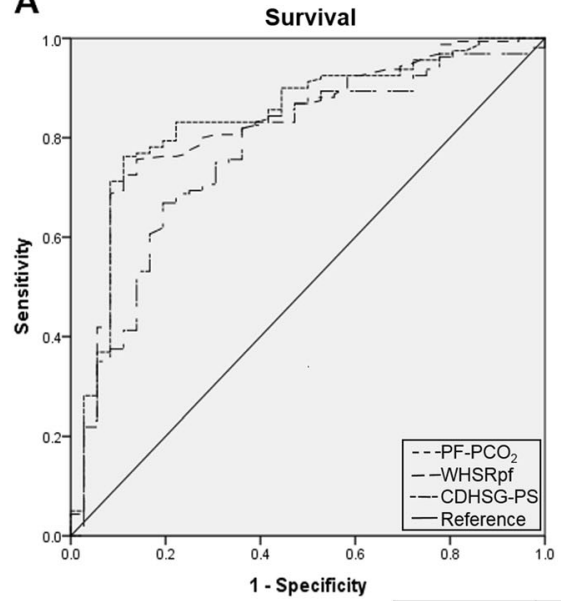

B

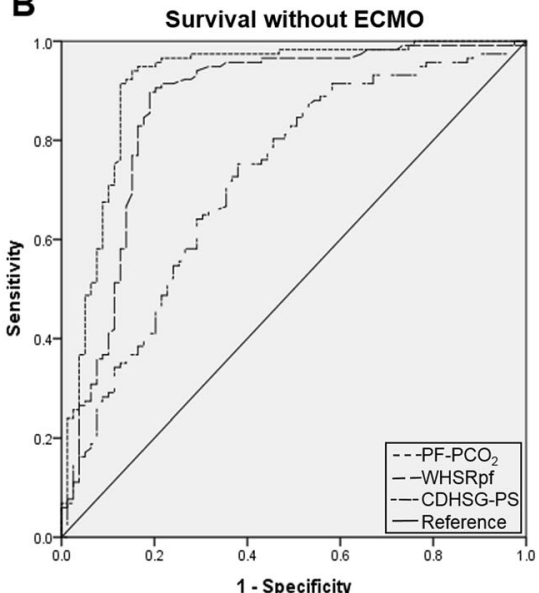

C

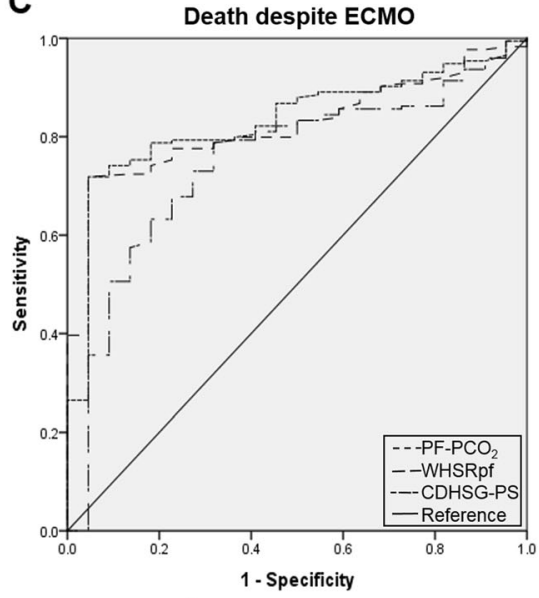

\begin{tabular}{|l|c|c|c|}
\hline & \multicolumn{3}{|c|}{ AUC (95\% Cl) } \\
\hline \multicolumn{1}{|c|}{ Tool } & A. Survival & B. Survival without ECMO & C. Death despite ECMO \\
\hline PF-PCO $_{2}$ & $0.84(0.77-0.91)$ & $0.92(0.87-0.96)$ & $0.83(0.76-0.91)$ \\
\hline WHSRpf & $0.80(0.72-0.88)$ & $0.87(0.81-0.93)$ & $0.82(0.75-0.89)$ \\
\hline CDHSG-PS & $0.77(0.69-0.86)$ & $0.72(0.65-0.80)$ & $0.75(0.65-0.85)$ \\
\hline Brindle & $0.74(0.65-0.83)$ & $0.75(0.68-0.82)$ & $0.77(0.67-0.88)$ \\
\hline
\end{tabular}

Fig. 2 AUC curves for each predictive tool. Brindle curves are not shown due to low AUC and opposite test direction compared to the other scores. ECMO extracorporeal membrane oxygenation, $C D H S G$ -
PS Congenital Diaphragmatic Hernia Study Group Probability of Survival Equation, WHSRpf Wilford Hall Santa Rosa Prediction Formula, $P F-P C O_{2}\left(\mathrm{PaO}_{2} / \mathrm{FiO}_{2}\right)-\mathrm{PCO}_{2}$ equation

\section{Discussion}

This retrospective review showed that, in our single center experience, the PF-PCO ${ }_{2}$ tool was superior to the CDHSGPS, Brindle, and WHSRpf tools for early postnatal prediction of survival in infants with $\mathrm{CDH}$. We also found the PF$\mathrm{PCO}_{2}$ tool to be most predictive of survival without ECMO, but not death despite ECMO. In our patient population, a score >-60 had an $84 \%$ PPV and $100 \%$ NPV to predict survival and a score $>+80$ had a $90 \%$ PPV and $89 \%$ NPV to predict survival without ECMO.

The CDHSG-PS and Brindle scores predicted survival the poorest in our patient population, with an AUC of 0.77 and 0.74 , respectively. Javid et al. [17] showed that survival rates for infants with $\mathrm{CDH}$ in the Canadian Neonatal Network were better than that predicted by the CDHSG-PS tool. Similar results were obtained by Downard et al. [18] in an analysis of their $\mathrm{CDH}$ population, where actual versus predicted survival was $93 \%$ versus $68 \%$, respectively. In contrast, Skarsgard et al. [12] and Baird et al. [19] found the CDHSG-PS tool predicted mortality well in their databases of infants with $\mathrm{CDH}$ from multiple centers in Canada. Gentili et al. [13] also found this model to be effective at predicting mortality (AUC 0.84 ) in their local population of infants with $\mathrm{CDH}$. Furthermore, the CDHSG-PS model significantly predicted survival in a local population of CDH infants who underwent ECMO [10]. Regarding the Brindle tool, the tool stratified infants into low, intermediate, and high risk for mortality categories with an AUC of 0.81 in the derivation model, but only 0.77 in the validation model [11]. Finally, Akinkuotu et al. [2] found the Brindle score to independently predict mortality at 6 months, but not risk for ECMO.

In our infants with $\mathrm{CDH}$, the WHSRpf tool predicted survival second best, with an AUC of 0.80. Authors applying this tool to their local populations have shown good prediction of survival or mortality, with Shultz et al. [8] showing an AUC of 0.87 in their local derivation model and Gentili et al. [13] an AUC of 0.84. However, the predictive ability declined when applied to larger databases $[8$, 17]. In a CDH-ECMO population, Hoffman et al. [20] found the WHSRpf tool predicted survival in $\mathrm{CDH}$ infants who underwent ECMO with an AUC of 0.71.

It is unclear why the CDHSG-PS and Brindle tools had lower predictive scores for survival, survival without ECMO, and death despite ECMO in our population. One reason could be that the authors of these tools did not exclude infants with other major cardiac or chromosomal anomalies, both of which would increase the risk of mortality via the Brindle score. As infants with other major anomalies may frequently not be offered (or parents may decline) surgical intervention or ECMO, we excluded this group of patients to isolate the effect of the diaphragmatic hernia on mortality. Additionally, we excluded infants born at a gestational age of less than $34^{0 / 7}$ weeks or birth weight less than $1800 \mathrm{~g}$, as ECMO is not typically offered to these patients $[21,22]$ and low birth weight and prematurity increase mortality $[11,22,23]$. Including these infants 
would likely reduce the predictive ability of the PF-PCO equation, as factors other than pulmonary function could play a role in an infants' death. Finally, we excluded infants diagnosed after $24 \mathrm{~h}$ of life, because these infants typically have a mild defect and favorable prognosis [3]. Among the 19 infants we excluded due to diagnosis after $24 \mathrm{~h}$, survival without ECMO was $100 \%$. Thus, for this group of $\mathrm{CDH}$ infants, a tool predicting survival seems unnecessary. As

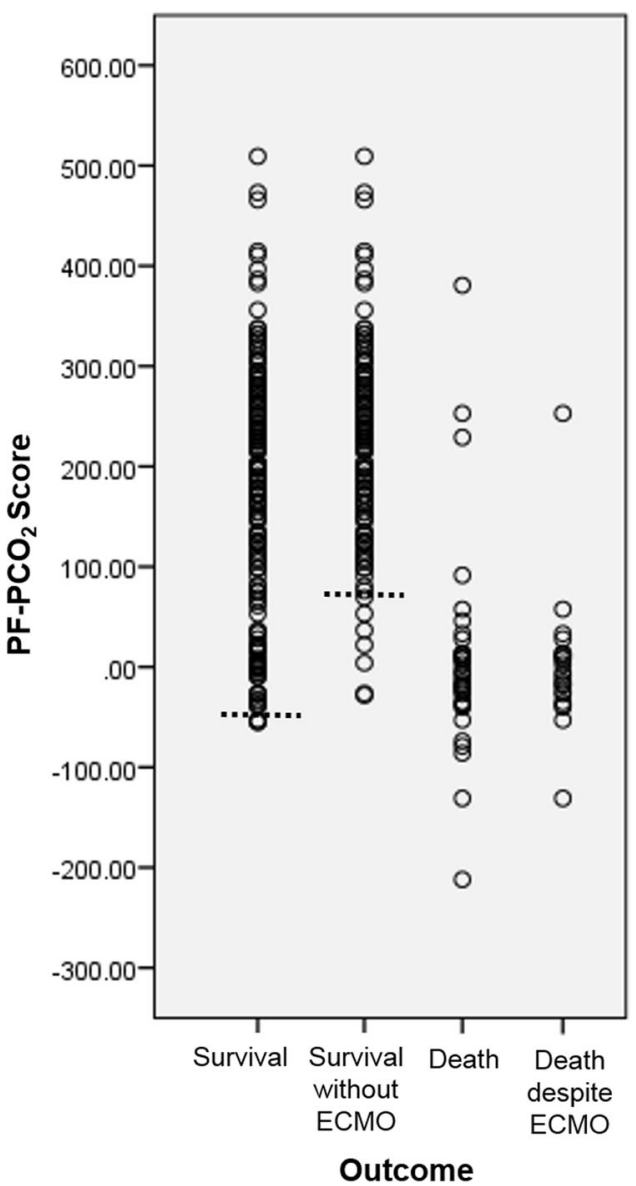

Fig. 3 Scatterplot of PF-PCO 2 values for outcomes of survival, survival without ECMO, death, and death despite ECMO. Dotted lines represent proposed optimal cutoff points of $>-60$ for survival and $>+80$ for survival without ECMO. PF-PCO $\left(\mathrm{PaO}_{2} / \mathrm{FiO}_{2}\right)-\mathrm{PCO}_{2}$ equation, ECMO extracorporeal membrane oxygenation expected, the WHSRpf score had good predictive ability, with an AUC of 0.80 for survival. The $\mathrm{PF}-\mathrm{PCO}_{2}$ score likely performed better due to the inclusion of the $\mathrm{PF}$ ratio, rather than $\mathrm{PaO}_{2}$ alone, thereby providing a better measure of oxygenation [14, 15]. An advantage of the PF-PCO score is the ease with which it can be calculated at the bedside, in contrast to the CDHSG-PS and Brindle tools, which are algorithm based.

Our findings suggest that incorporating a better measure of oxygenation and ventilation allows the $\mathrm{PF}-\mathrm{PCO}_{2}$ tool to predict survival and survival without ECMO in infants $\geq 34$ weeks gestation with isolated $\mathrm{CDH}$. The severity of pulmonary hypoplasia determines outcome in these patients, including need for ECMO and mortality [2, 7-10]. Infants with $\mathrm{CDH}$ have decreased numbers of alveoli and accompanying vessels compared to normal term infants, although the total ratio is normal [24]. Furthermore, there is a greater percentage of peripheral arteries that are abnormally muscularized or hypertrophied [24], also contributing to pulmonary hypertension. When correlating postmortem findings with blood gas values, Germain et al. [25] found that the severity of pulmonary hypoplasia correlated with the level of hypoxemia in $\mathrm{CDH}$ infants. Finally, other investigators have shown that blood gas values predict survival in infants with $\mathrm{CDH}$, including $\mathrm{PaCO}_{2}$ [26] and the highest $\mathrm{FiO}_{2}$ [9] and $\mathrm{PaO}_{2}$ [27, 28]. Regarding ECMO risk, Kays et al. [29] showed that $\mathrm{PaCO}_{2}$ and $\mathrm{PaO}_{2}$ at $1 \mathrm{~h}$ of life correlated with an increased risk for ECMO in their group of infants with severe $\mathrm{CDH}$, while Hoffman et al. [30] found that $\mathrm{PaCO}_{2}$ independently predicted survival in $\mathrm{CDH}$ infants placed on ECMO. However, $\mathrm{PaO}_{2}$ itself is not the best measure of oxygenation in a patient. Of the various measures of oxygenation or hypoxemia [14, 15], the PF ratio is easy to calculate and has been shown to be significantly different between survivors and non-survivors of $\mathrm{CDH}$ [13].

While most studies have looked at survival or mortality alone, we also determined the ability of the $\mathrm{PF}-\mathrm{PCO}_{2}$ equation to predict survival without ECMO and death despite ECMO. The equation performed well for predicting survival without ECMO, but not for death despite ECMO. These outcomes are clinically relevant, because infants with
Table 3 Positive and negative predictive values for the PF$\mathrm{PCO}_{2}$ tool at various cutoff points for outcomes of survival and survival without ECMO. Death despite ECMO is not shown due to poor predictive ability at all cut offs

\begin{tabular}{|c|c|c|c|c|c|c|c|c|c|c|}
\hline \multirow[t]{2}{*}{ Outcome } & & \multicolumn{9}{|l|}{ Cutoff } \\
\hline & & $>-80$ & $>-60$ & $>-40$ & $>-20$ & $>0$ & $>+20$ & $>+40$ & $>+60$ & $>+80$ \\
\hline \multirow[t]{2}{*}{ Survival } & PPV & $83 \%$ & $84 \%$ & $84 \%$ & $87 \%$ & $90 \%$ & $94 \%$ & $95 \%$ & $97 \%$ & $97 \%$ \\
\hline & NPV & $100 \%$ & $100 \%$ & $64 \%$ & $54 \%$ & $50 \%$ & $48 \%$ & $45 \%$ & $46 \%$ & $43 \%$ \\
\hline \multirow[t]{2}{*}{ Survival without ECMO } & PPV & $61 \%$ & $61 \%$ & $63 \%$ & $68 \%$ & $74 \%$ & $83 \%$ & $87 \%$ & $88 \%$ & $90 \%$ \\
\hline & NPV & $100 \%$ & $100 \%$ & $100 \%$ & $92 \%$ & $95 \%$ & $95 \%$ & $93 \%$ & $91 \%$ & $89 \%$ \\
\hline
\end{tabular}

Bolded values indicate optimal predictive cutoff for each outcome

ECMO extracorporeal membrane oxygenation 
$\mathrm{CDH}$ who require ECMO have a greater risk of mortality and long-term morbidity, including adverse neurodevelopmental outcomes and chronic lung disease [3, 31]. Thus, knowledge of an infants' risk for ECMO and death despite ECMO is important not only when considering the risks versus benefits of ECMO, but also when providing informed consent to families regarding this intervention. To date, no model has shown good predictive ability for the isolated outcome of death despite ECMO with $\mathrm{CDH}$.

There are several limitations to this study. This study may have limited generalizability, given that it was a retrospective review conducted at a single center serving a predominantly Caucasian population. Differences in initial care may have contributed to patient outcome, as $42 \%$ and $34 \%$ of patients in the survived and died groups, respectively, were outborn. Sample size is also relatively small. Additionally, differences in ventilator management can affect $\mathrm{PaCO}_{2}, \mathrm{PaO}_{2}$, and $\mathrm{FiO}_{2}$, which may produce different results in another center. Although our center has written guidelines directing the care of infants with $\mathrm{CDH}$, including a gentle ventilation strategy with relative permissive hypercapnia and criteria for ECMO initiation, we do not have data on compliance with this protocol. We also did not assess whether including ventilator parameters, particularly mean airway pressure, would change the predictive ability of the $\mathrm{PF}-\mathrm{PCO}_{2}$ equation. Finally, we were unable to validate the $\mathrm{PF}-\mathrm{PCO}_{2}$ tool in another population, including the CDHSG registry, as it does not contain data on $\mathrm{FiO}_{2}$. Thus, while we showed good predictive ability of this tool in our population, this may decline when applied to a different population. We plan to test this tool in a much larger independent data set.

This study's strengths include use of a prospectively maintained database with multiple data points, including physiologic measures of respiratory function as well as morbidity and mortality information. Additionally, data were available for all patients to calculate CDHSG-PS and Brindle scores and all but 7 patients to calculate WHSRpf and $\mathrm{PF}-\mathrm{PCO}_{2}$ scores. Furthermore, our exclusion criteria attempted to hone in on a subpopulation of $\mathrm{CDH}$ infants in whom a predictive tool would be clinically useful. Specifically, CDH infants, who are eligible for ECMO $\left(\geq 34^{0 / 7}\right.$ weeks gestation and $>1800 \mathrm{~g}$ ), do not have a mild defect (diagnosed $<24 \mathrm{~h}$ of life), and do not have other conditions that could influence their outcome. Although this study was limited to a single center, the University of Utah and Primary Children's Hospital NICU's are academic level III and IV units, respectively, and receive neonatal and maternal transfers from across Utah and neighboring states. Finally, despite this study covering a long time period, there were no differences in survival of or ECMO use in patients with $\mathrm{CDH}$.
In summary, the $\mathrm{PF}-\mathrm{PCO}_{2}$ tool predicted survival better than the CDHSG-PS, Brindle, and WHSRpf tools in our local population of infants with $\mathrm{CDH}$. This easy to use clinical tool may aid in postnatal therapeutic decisions and counselling of families of $\mathrm{CDH}$ infants. Further studies applying this tool to other populations are necessary to validate this equation. Additional studies should also consider analysis of the $\mathrm{PF}-\mathrm{PCO}_{2}$ tool at different time points within the first $24 \mathrm{~h}$ of life.

Author contributions Dr. MS performed the data analysis and prepared the manuscript. Dr. SF was involved in study design and manuscript review. Dr. BY developed and maintained the database and was involved in study design and manuscript review.

Conflict of interest The authors declare that they have no conflict of interest.

Publisher's note: Springer Nature remains neutral with regard to jurisdictional claims in published maps and institutional affiliations.

\section{References}

1. Lally KP, Jaksic T, Wilson JM, Clark RH, Hardin WD, Ronald $\mathrm{BH}$, et al. Estimating disease severity of congenital diaphragmatic hernia in the first $5 \mathrm{~min}$ of life. J Pediatr Surg. 2001;36:141-45.

2. Akinkuotu AC, Cruz SM, Abbas PI, Lee TC, Welty SE, Olutoye $\mathrm{OO}$, et al. Risk stratification of severity for infants with $\mathrm{CDH}$ : prenatal versus postnatal predictors of outcome. J Pediatr Surg. 2016;51:44-48.

3. Losty PD. Congenital diaphragmatic hernia: where and what is the evidence? Semin Pediatr Surg. 2014;23:278-82.

4. Murthy K, Pallotto EK, Gien J, Brozanski BS, Porta NFM, Zaniletti I, et al. Predicting death or extended length of stay in infants with congenital diaphragmatic hernia. J Perinatol. 2016;36:654-59.

5. Cannie M, Jani J, Meersschaert J, Allegaert K, Marchal G, Deprest $J$, et al. Prenatal prediction of survival in isolated diaphragmatic hernia using observed to expected total fetal lung volume determined by magnetic resonance imaging based on either gestational age or fetal body volume. Ultrasound Obstet Gynecol. 2008;32:633-39.

6. Bebbington M, Victoria T, Danzer E, Moldenhauer J, Khalek N, Johnson $\mathrm{M}$, et al. Comparison of ultrasound and magnetic resonance imaging parameters in predicting survival in isolated leftsided congenital diaphragmatic hernia. Ultrasound Obstet Gynecol. 2014;43:670-74.

7. Numanoglu A, Morrison C, Rode H. Prediction of outcome in congenital diaphragmatic hernia. Pediatr Surg Int. 1998;13:564-68.

8. Shultz CM, DiGeronimo RJ, Yoder BA. Congenital diaphragmatic hernia: a simplified postnatal predictor of outcome. J Pediatr Surg. 2007;42:510-16.

9. Lupo E, Castoldi F, Maestri L, Rustico M, Dani C, Lista G. Outcome of congenital diaphragmatic hernia: analysis of implicated factors. Minerva Pediatr. 2013;65:279-85.

10. Chiu PPL, Sauer C, Mihailovic A, Adatia I, Bohn D, Coates AL, et al. The price of success in the management of congenital diaphragmatic hernia: is improved survival accompanied by an increase in long-term mortality? J Pediatr Surg. 2006;41:888-92. 
11. Brindle ME, Cook EF, Tibboel D, Lally PA, Lally KP. A clinical prediction rule for the severity of congenital diaphragmatic hernias in newborns. Pediatrics . 2014;134:e413-19.

12. Skarsgard ED, MacNab YC, Qiu Z, Little R, Lee SK. SNAP-II predicts mortality among infants with congenital diaphragmatic hernia. J Perinatol. 2005;25:315-19.

13. Gentili A, Pasini L, Lannella E, Landuzzi V, Lima M, Bacchi Reggiani ML, et al. Predictive outcome indexes in neonatal congenital diaphragmatic hernia. J Matern Fetal Neonatal Med. 2015;28:1602-07.

14. Aboab J, Louis B, Jonson B, Brochard L. Relation between $\mathrm{PaO}_{2} /$ $\mathrm{FiO}_{2}$ ratio and $\mathrm{FiO}_{2}$ : a mathematical description. Intensive Care Med. 2003;32:1494-97.

15. Ferguson ND, Fan E, Camporota L, Antonelli M, Anzueto A, Beale R, et al. The Berlin definition of ARDS: an expanded rationale, justification, and supplementary material. Intensive Care Med. 2012;38:1573-82.

16. Chandrasekharan P, Konduri G, Basir M, Klein J, Lakshminrusimha S. Risk stratification for congenital diaphragmatic herniais it all oxygenation but not ventilation? [Letter]. J Perinatol. 2018;38:608-09.

17. Javid PJ, Jaksic T, Skarsgard ED, Lee S., the Canadian Neonatal Network. Survival rate in congenital diaphragmatic hernia: the experience of the Canadian neonatal network. J Pediatr Surg. 2004;39:657-60.

18. Downard CD, Jaksic T, Garza JJ, Dzakovic A, Nemes L, Jennings $\mathrm{RW}$, et al. Analysis of an improved survival rate for congenital diaphragmatic hernia. J Pediatr Surg. 2003;38:729-32.

19. Baird R, MacNab YC, Skarsgard ED. Mortality prediction in congenital diaphragmatic hernia. J Pediatr Surg. 2008;43:783-87.

20. Hoffman SB, Massaro AN, Gingalewski C, Short BL. Survival in congenital diaphragmatic hernia: use of predictive equations in the ECMO population. Neonatology . 2011;99:258-65.

21. Gray B, Rintoul N. Guidelines for neonatal respiratory failure. In: ELSO Guidelines for Cardiopulmonary Extracorporeal Life Support. Extracorporeal life support organization. Ann Arbor. 2017. https://www.elso.org/Resources/Guidelines.aspx. Accessed Aug 30, 2018.
22. Chandrasekharan PK, Rawat M, Madappa R, Rothstein DH, Lakshminrusimha S. Congenital diaphragmatic hernia—a review. Matern Health Neonatol Perinatol. 2017; 3:6. https://doi.org/10. 1186/s40748-017-0045-1.

23. Shanmugam H, Brunelli L, Botto LD, Krikov S, Feldkamp ML. Epidemiology and prognosis of congenital diaphragmatic hernia: a population-based cohort study in Utah. Birth Defects Res. 2017;09:1451-59.

24. Bohn D, Tamura M, Perrin D, Barker G, Rabinovitch M. Ventilatory predictors of pulmonary hypoplasia in congenital diaphragmatic hernia, confirmed by morphologic assessment. J Pediatr. 1987;111:423-31.

25. Germain JF, Farnoux C, Pinquier D, Cortez A, Hartmann JF, Sibony $\mathrm{O}$, et al. Can blood gas values predict pulmonary hypoplasia in antenatally diagnosed congenital diaphragmatic hernia? J Pediatr Surg. 1996;31:1634-39.

26. Salas AA, Bhat R, Dabrowska K, Leadford A, Anderson S, Harmon $\mathrm{CM}$, et al. The value of $\mathrm{PaCO}_{2}$ in relation to outcome in congenital diaphragmatic hernia. Am J Perinatol. 2014;31:939-46.

27. Kays DW, Islam S, Perkins JM, Larson SD, Taylor JA, Talbert JL. Outcomes in the physiologically most severe congenital diaphragmatic $(\mathrm{CDH})$ patients: whom should we treat? J Pediatr Surg. 2015;50:893-97.

28. Wilson JM, Lund DP, Lillehei CW, Vacanti JP. Congenital diaphragmatic hernia: predictors of severity in the ECMO era. J Pediatr Surg. 1991;26:1028-34.

29. Kays DW, Talbert JL, Islam S, Larson SD, Taylor JA, Perkins J. Improved survival in left liver-up congenital diaphragmatic hernia by early repair before extracorporeal membrane oxygenation: optimization of patient selection by multivariate risk modeling. J Am Coll Surg. 2016;222:459-70.

30. Hoffman SB, Massaro AN, Gingalewski C, Short BL. Predictors of survival in congenital diaphragmatic hernia patients requiring extracorporeal membrane oxygenation: CNMC 15-year experience. J Perinatol. 2010;30:546-52.

31. Leeuwen L, Fitzgerald DA. Congenital diaphragmatic hernia. J Paediatr Child Health. 2014;50:667-73. 